Article

\title{
Unconventional Excess Heat Sources for District Heating in a National Energy System Context
}

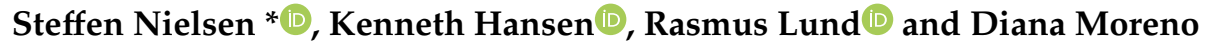 \\ Department of Planning, Aalborg University, Rendsburggade 14, 9000 Aalborg, Denmark; keha@ens.dk (K.H.); \\ rl@planenergi.dk (R.L.); diana@plan.aau.dk (D.M.) \\ * Correspondence: steffenn@plan.aau.dk
}

Received: 26 August 2020; Accepted: 24 September 2020; Published: 27 September 2020

check for updates

\begin{abstract}
District heating (DH) is an important technology in future smart energy systems as it allows for an efficient implementation of various renewable energy sources. As DH develops towards lower temperatures and renewable electricity production increases, new types of heat sources become relevant. Thus, the aim of this article is to assess the potential for utilizing four unconventional excess heat (UEH) sources in DH systems, namely: Data centers, wastewater treatment, metros and service sector buildings. The main method used to assess the UEH potentials is an energy system analysis focusing on the availability and economic feasibility of utilizing the UEH sources in national contexts. The analysis consists of 2015 and 2050 scenarios for Germany, Spain and France. The results show a potential for utilizing the UEH potentials in all three countries, both in 2015 and 2050 systems. The potentials are highest in the 2050 scenarios, primarily due to larger DH shares. Furthermore, the potentials are limited by competition with other heat supply sources, conjunction with heat demands and feasible heat pump operation. In conclusion, the four UEH sources could impact the local DH systems, but in a national energy system context they are expected to play a minor role.
\end{abstract}

Keywords: energy planning; district heating; energy systems analysis; heat pumps; excess heat

\section{Introduction}

With most countries having ratified the Paris Agreement [1] and thereby ensuring the long-term climate targets, the focus has turned towards technological solutions that can contribute to the realisation of the goals. A central concept introduced within recent years is the notion of smart energy systems [2,3]. The basic idea behind smart energy systems is to find the best solutions by applying a holistic approach, examining solutions across various energy infrastructures, namely electricy, heating and gas networks, but also different energy sectors such as transport and industries. In connection to the smart energy system concept there has also been a revival of the benefits of utilising DH in urban areas, as these systems allow for more renewable energy integration in the overall energy systems, technologies such as combined heat and power (CHP) plants, excess heat from industries [4] and waste incineration, solar thermal, geothermal as well as large scale heat pumps. However, there is a general need to develop the $\mathrm{DH}$ systems towards the so-called fourth generation $\mathrm{DH}[5,6]$. The fourth generation $\mathrm{DH}$ is characterized by forward temperatures that are reduced to $55^{\circ} \mathrm{C}$ from typically $70-90{ }^{\circ} \mathrm{C}$ of today's modern systems, minimizing network losses, allowing for a more efficient supply system that has a better integration of both lower temperature renewable heat sources and waste heat [7]. The heat sources with temperatures similar to that of the DH system can be used directly, while other heat sources need to be boosted by, e.g., electrical heat pumps. The closer the heat sources are to the required temperature in the DH systems, the lower the energy needed to boost the temperature. Figure 1 illustrates the principal concept of using excess heat sources in DH systems. Generally, in current DH systems, high temperature industrial excess heat sources are attractive and 
typically named conventional excess heat sources. Conventional excess heat sources are typically either waste heat from thermal power generation or waste heat from high temperature industrial processes. However, with the move towards the fourth generation DH concept, lower temperature heat sources become relevant as well. These sources typically need boosting from heat pumps to achieve the relevant temperature level. The closer the source temperature is to the temperature required by the $\mathrm{DH}$ system, the better the seasonal coefficient of performance (SCOP) [8].

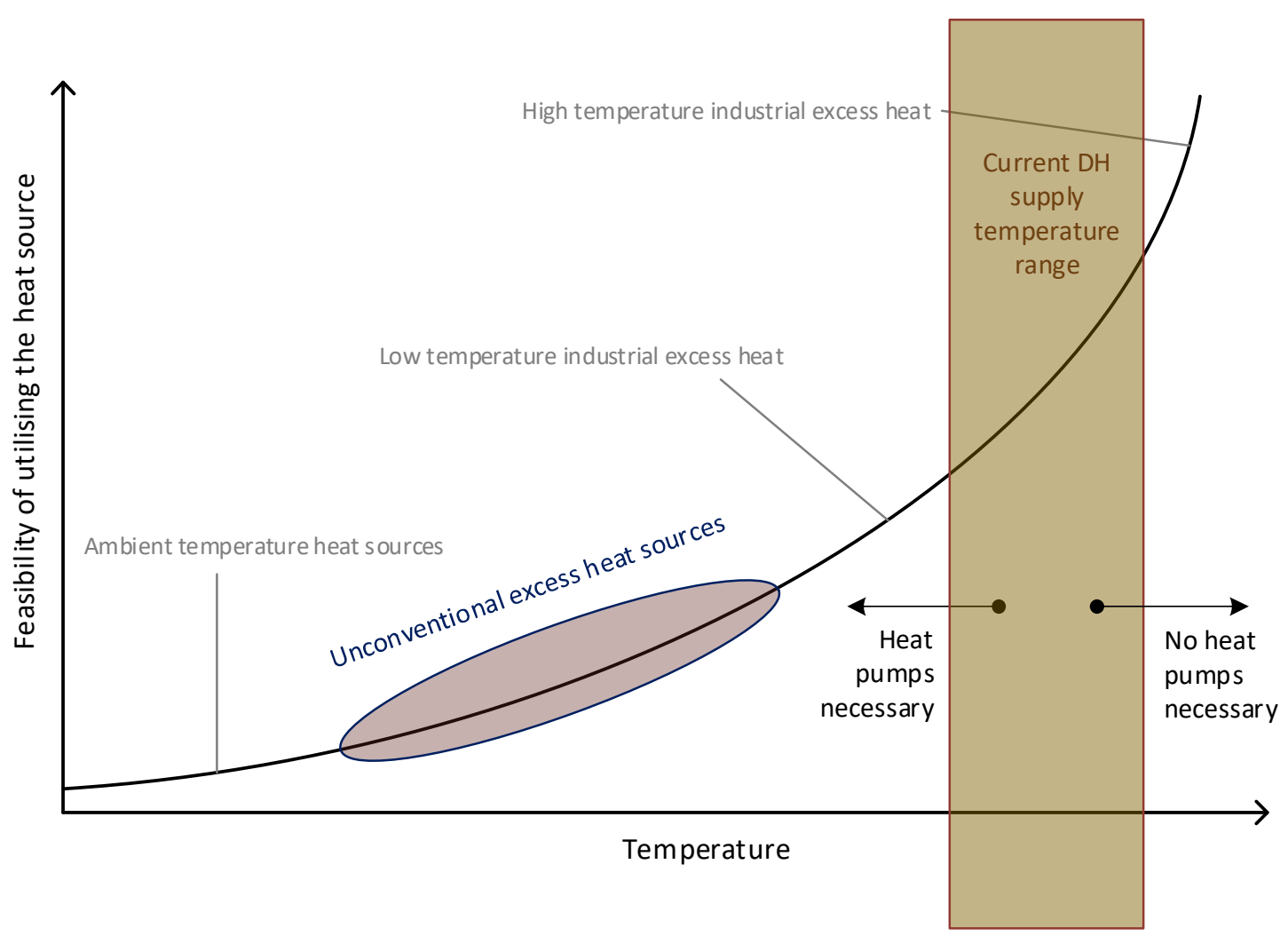

Figure 1. Principal diagram illustrating the increasing feasibility of heat sources with increasing temperatures. Heat sources with temperatures above the district heating $(\mathrm{DH})$ supply temperature might be utilized without a heat pump. However, to utilize a heat source with a lower temperature, a heat pump is needed.

\subsection{Current Research on Unconventional Excess Heat Sources}

UEH sources typically include rejected heat from cooling systems in, e.g., data centers, buildings, food production, and supermarkets. UEH also covers rejected heat from metro ventilation systems and wastewater treatment facilities. Some of these heat sources are especially relevant to DH, as they are located close to urban infrastructures. There are examples of supermarkets recovering heat from their own refrigeration systems to supply space heat for the supermarket [9]. This literature review focuses on the application of excess heat in DH systems.

In [10] DH systems in general are analyzed, showing both economic and environmental benefits of $\mathrm{DH}$ systems. The article categorizes $\mathrm{DH}$ according to technologies and, amongst others, discusses the benefits of utilizing industrial waste heat. In [11] a methodology for mapping industrial waste heat on a national level is proposed, where the energy consumed in different energy intensive industries was used to estimate the excess heat potentials. Similarly, in [12] the heat demands of European industries are estimated by temperature level and branch in different approaches, with different temperature levels of process heat. Excess heat potentials have also been assessed on a national level, for instance in the United Kingdom [13] where around $90 \%$ of the energy intensive industries has been covered, resulting in around 36-71 PJ annually being technically feasible. Another article [14], focuses on 
developing a method to assess the excess heat potential for DH in Denmark. The method uses industry sector specific temperature levels to find the directly available potentials and the potentials needing a temperature boost. In total it is estimated that around $5.1 \%$ of the current heat demand can be provided by excess heat in the analyzed area. There are also several local case studies of excess heat utilization in DH where Milan [15], Hamburg [16], Chifeng [17] and Shinchi [18] are just a few recent examples. Furthermore, some articles $[19,20]$ have a strong focus on the GHG emission impacts of utilizing excess heat in DH systems, and different methods for assessing these. Brueckner et al. [21] review different methods for estimating industrial waste heat potentials and conclude that a wide variety of methods exists, mostly depending on data availability. As many countries do not have country specific data, key numbers are used from other countries. Finally, a few articles deal with the organizational aspects of implementing excess heat into DH systems, where ref. [22] focuses on risks, ref. [23] on policy impacts, ref. [24] on actor dynamics and ref. [25] on third party access.

In regard to UEH, most research concentrates on cases showcasing specific types of excess heat sources and the following part presents some recent examples. In [26], the excess heat potential from wastewater treatment facilities in Ireland was analyzed in a spatio-temporal analysis, showing that $58-93 \%$ of the heat demand can be covered by heat recovery in five different zones. Another article, [27], examines the economically feasible potential for waste heat recovery from wastewater treatment in Hungary, where distance to $\mathrm{DH}$ and investments in heat pumps were found to be the major factors influencing the feasibility. Another UEH is waste heat recovery from data centers. A recent review paper [28] shows the current status of the technologies for data center refrigeration but also shows that at least 17 different projects are currently reusing waste heat from data centers. In [29], the feasibility of using excess heat for DH from an air cooled data center in Spain is analyzed. In addition, there are recent examples from China [30], Northern Europe [31], Finland [32] and Denmark [33], all showing how to integrate data center excess heat recovery with $\mathrm{DH}$ systems, in an economically, environmentally and energy efficient manner. Finally, there are also a few articles on other UEH, however, these sources are not as prevalent as wastewater treatment and data centers. One article focuses on utilizing excess heat from metro systems in London [34], another on excess heat from service sector cooling and refrigeration processes [35], and a third on excess heat from $\mathrm{CO}_{2}$ refrigeration systems in supermarkets [36]. When compared with the other research, this paper opted for an even more specific focus within UEH sources. Wastewater treatment facilities being universal, data centers becoming popular as digitalization develops, as well as metro and service sectors cooling and ventilation systems, the authors consider their assessment as unconventional yet essential UEH sources for both current and future energy system analysis.

\subsection{Scope of the Article}

The literature review clearly shows that utilizing excess heat in DH is a well-established research field, with many different topics dealing with technical, economic, environmental, organizational and policy aspects. In terms of utilizing the conventional excess heat sources, more research is available, while research on UEH is still limited. The majority of the research on UEH is on specific local case studies and reviews on specific resources, such as data centers. On the other hand, a lot of research focuses on future national energy systems and DH, where UEH is omitted or only included to a limited extent. Thus, a research gap can be identified, as it is vital to assess the wider application of UEH sources in DH systems, in relation to the national energy systems. Although the understanding of the unconventional nature of these heat sources is yet to be addressed in the academia, this paper points out and exacerbates their potential role within a national complete spectrum of heating sources and their compatibility with current and planned DH systems. The paper rises awareness, adds to its unconventional understanding and encourages research on the area by showcasing national current and future simulations. Therefore, this article aims to identify the potential of four of the main UEH sources, as well as its role in both existing energy systems and future energy systems. The four UEH sources examined in the article are: Data center cooling systems, wastewater treatment, metro ventilation 
and cooling from the service sector. Additionally, the methodology proposed aiming at identifying accessible excess heat, combines spatial mapping, available heat temporal distributions for national energy system scenarios. Here, the paper reproduces alternative scenarios where the impact of UEH sources is determined on a national system level.

The analysis is carried out as part of the EU project ReUseHeat [37] and is partly based on the analysis presented in [38], with the more specific aim of identifying the role of UEH in national energy systems. The analysis focuses on the three countries Germany, Spain, and France in order to showcase countries with large variation in climate, energy systems as well as available excess heat sources. The analysis is based on national energy system analysis including all energy sectors; heating, cooling, transport, industry, and electricity. The utilization of UEH sources is restricted to what is available for $\mathrm{DH}$, which is sensible as it provides benefits in terms of flexibility and ensuring a certain level of demand for heat. The results and conclusions primarily focus on the savings in primary energy and energy system costs of the implementing UEH on a national level, but also the total accessible UEH potential as well as the feasible share of this total.

\section{Methods}

To analyze the four UEH sources in three different countries, a specific analytical approach is used. This is explained in Section 2.1 together with the scenarios, followed by descriptions of the cost and fuel price assumptions, energy system analysis, as well as the algorithms for estimating the accessible excess heat.

\subsection{Analytical Approach and Scenario Structure}

To give an overview, the analytical approach is summarized in Figure 2.

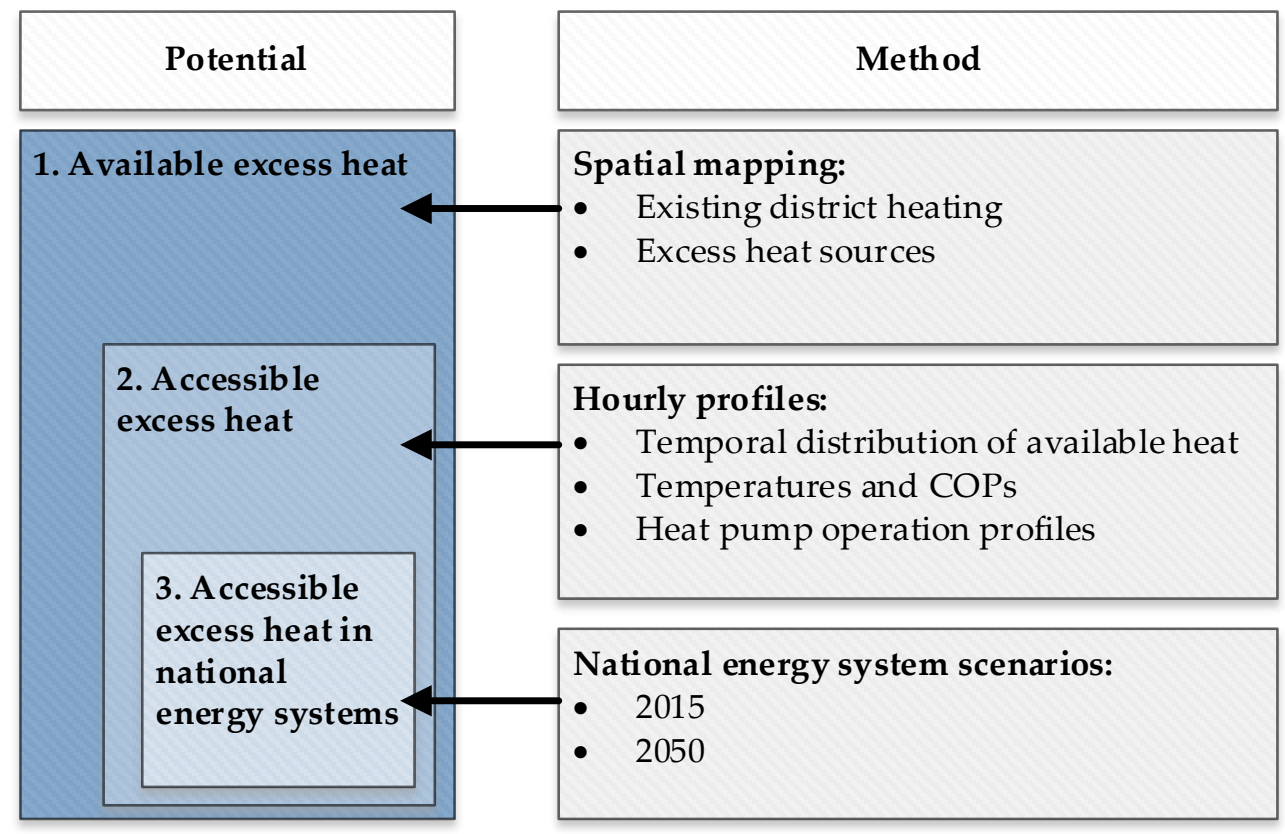

Figure 2. Analytical approach to estimating the excess heat potentials.

A key concept in this article is the difference between available and accessible excess heat, where the first is the heat available at the source at any temperature, and the latter is the heat supplied by a compression heat pump boosted to the required temperature level. In other words, the accessible heat is the sum of the available heat and the electricity required for the heat pump to boost the heat source. The first part of the analytical approach is the assessment of the available excess heat, which is estimated using spatial mapping of both excess heat sources and distance to DH, based on [39]. 
The second part, the accessible excess heat, focuses on the temporal distribution of the heat sources creating hourly profiles for the excess heat sources, estimating COPs and operation profiles of the heat pumps. Finally, the first two parts are integrated into the national energy system analysis in the third part. The third part is the main focus of this article. Here, the relevant national energy system models are identified. As the UEH sources can be relevant in a current context as well as in future energy systems, both will be analyzed. In the analysis, two different scenarios from the Heat Roadmap Europe Project are used. The reference scenario for the year 2015 and the Heat Roadmap Europe scenario for 2050 are used and can be studied further in [40]. The 2015 scenarios represent the national energy systems of today, while the 2050 scenarios have a larger share of $\mathrm{DH}$ and end-use savings in buildings. The 2015 scenarios are based on the JRC-EU-TIMES models which were further developed into EnergyPLAN models [40]. The annual values are similar in both models, but the main difference is that the hourly dimension was added in the EnergyPLAN model. The DH shares in 2015 for the three countries differ a lot from $12 \%$ in Germany, $5 \%$ in France, and 1\% in Spain. Due to the low DH shares in France and Spain in the 2015 scenario, these were expanded to $12 \%$, the EU average, to enable a discussion of whether the excess heat sources are only feasible in future energy systems or systems that resemble current energy systems. Furthermore, the 2015 state of DH in the three countries is as follows: In Germany, DH served 12,338,611 citizens, based on $42 \%$ coal, $39 \%$ natural gas, $18 \%$ renewables, and $2 \%$ other. In France, DH served 5,424,000 citizens based on 53\% renewables, 38\% natural gas, $7 \%$ coal, and 3\% other. In Spain, DH served 117,550 citizens with the following fuel mix $47.38 \%$ natural gas, $25.85 \%$ renewables, and $26.77 \%$ other [ 41$]$.

The heating sector is only part of the whole energy system, and as many of the future solutions are related to the design of the overall system, it becomes important to know the structure of these systems. Therefore, Figure 3 shows an overview of the primary energy supply in both scenarios for Spain, Germany and France. The primary energy supply in the 2015 scenario for Spain shows a 70\% share of fossil fuels, primarily oil, and natural gas. In Germany in 2015, the fossil fuel share is around $75 \%$, where coal plays a significant role. In France, the fossil fuel share is $40 \%$ mainly consisting of coal and gas but also with a significant share of nuclear of around $48 \%$. The 2050 scenarios are significantly different, with high renewable shares. Spain is dominated by biomass and solar, Germany biomass and wind, while France is dominated by biomass, wind, and nuclear.

In addition to Figure 3, there are many underlying aspects of the 2050 scenarios, the following explains the main developments within each sector. In the residential and commercial buildings heat efficiency measures are implemented and the supply is gradually electrified, the heat savings are largest in the residential sector. In the transport sector there is an increase in demand, which corresponds to the share of transport that is electrified. The industrial sector increases its energy demand and the share of electricity and biomass in the fuel mix. Finally, the agricultural sector is assumed to be at the same level for 2015 as 2050 [40]. As mentioned previously, the DH share has increased, specifically in Spain from $1 \%$ to $73 \%$, in Germany from $21 \%$ to $60 \%$ and in France from $9 \%$ to $33 \%$. These relatively large increases in DH shares are based on what was found feasible in the Heat Roadmap Europe studies, where different shares were analyzed for each country. It should be noted that these shares are very important as they set the limits for how much UEH can be used. With lower DH shares, the potential for UEH is expected to be lower as well. Furthermore, the supply of DH is to a large extent based on excess heat from high-temperature processes, such as industries, waste incineration plants, CHP plants and electrofuel production facilities. The scenarios also include a large share of electric heat pumps using ambient heat sources.

As the 2050 scenarios are already optimized in terms of heat pumps, a modified 2050 scenario without heat pumps is used in this article. In relation to this, the heat pumps implemented are based on the feasible utilization, which represents the most efficient use of heat pumps according to the needs of the energy system. Furthermore, each of the four excess heat sources are analyzed individually as well as in a combined heat source scenario. 
Finally, to evaluate the scenarios the following parameters are examined: Total energy system costs, primary energy supply, $\mathrm{CO}_{2}$-emissions, excess electricity generation, installed heat pump capacity, heat pump capacity factors and utilized accessible excess heat.

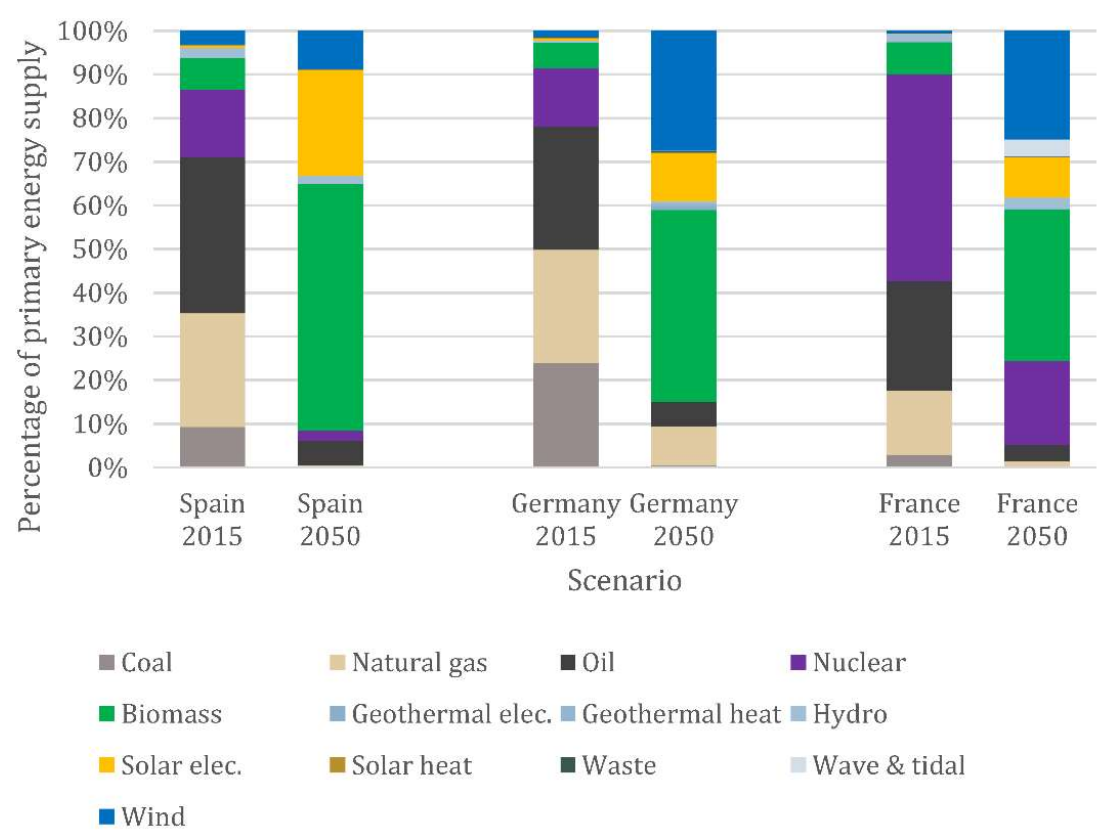

Figure 3. Primary energy supply in the Heat Roadmap Europe scenarios for Spain, Germany, and France [40].

\subsection{Cost and Fuel Price Assumptions}

As described in the analytical approach, the scenarios from the Heat Roadmap Europe 4 (HRE4) project [42] are used as the point of departure of the analysis. Thus, the same technical specifications and economic parameters are used, and further explanations are available in the HRE4 cost database [43]. However, as the UEH sources are not examined in the original HRE4 scenarios, both data on the costs of heat pumps and availability of UEH sources will be explained here.

Table 1 presents the DH heat pump costs, which shows that the investment costs increase from 2015 to 2050 and that the costs vary between the three countries, showing lowest costs in Spain and highest costs in France. The difference in heat pump investment costs between the countries is mainly due to a difference in the labor costs component. In addition, the table also shows the fuel price assumptions used for each country, mainly showing differences in the costs of wood pellets and local biomass as well as an increase in oil and gas prices between 2015 and 2050.

Table 1. Cost assumptions for DH heat pumps and fuel prices for the three countries in 2015 and 2050. Heat pump costs are based on [44] and the fuel price assumptions are based on the World Energy Outlook of the International Energy Agency, "Sustainable development scenario" from 2017 [45].

\begin{tabular}{cccccccc}
\hline Parameter & \multirow{2}{*}{ Unit } & \multicolumn{2}{c}{ Germany } & \multicolumn{2}{c}{ Spain } & \multicolumn{2}{c}{ France } \\
& & $\mathbf{2 0 1 5}$ & $\mathbf{2 0 5 0}$ & $\mathbf{2 0 1 5}$ & $\mathbf{2 0 5 0}$ & $\mathbf{2 0 1 5}$ & $\mathbf{2 0 5 0}$ \\
\hline Heat pumps & & & & & & & \\
Investment cost & M€/MW-e & 2.39 & 3.04 & 2.22 & 2.84 & 2.39 & 3.09 \\
Fixed operation and maintenance & \% of investment pr. year & 0.28 & 0.38 & 0.28 & 0.38 & 0.28 & 0.38 \\
Technical lifetime & years & 25 & 25 & 25 & 25 & 25 & 25 \\
Fuel prices & & & & & & & \\
Coal & $€ / G J$ & 2.4 & 2.4 & 2.4 & 2.4 & 2.4 & 2.4 \\
Oil & $€ / G J$ & 7.6 & 12.1 & 7.6 & 12.1 & 7.6 & 12.1 \\
Gas & $€ / G J$ & 5.7 & 9.3 & 5.7 & 9.3 & 5.7 & 9.3 \\
Wood pellets & $€ / G J$ & 7.7 & 9.4 & 7.7 & 9.5 & 7.7 & 9.3 \\
Local biomass & $€ / G J$ & 7.9 & 7.9 & 7.4 & 7.4 & 8.1 & 8.1 \\
\hline
\end{tabular}




\subsection{Energy System Analysis}

Several energy system analysis tools are available when examining national energy systems [46-48], but in this article the widely known EnergyPLAN tool is used [49]. To give a few examples of the versatility of the tool, EnergyPLAN has recently been used for an extensive range of energy systems analyses, from a national analysis of Ireland [50] examining the role of smart energy markets [51] down to a local analysis of optimal heat savings potentials in a DH system [52]. Figure 4 presents an overview of the inputs, options, and outputs of the EnergyPLAN tool. In relation to the focus in this article, the EnergyPLAN tool is relevant as it deals with national energy systems and DH is an integral part of the tool, with options to simulate heat production from a variety of sources on an hourly basis. Finally, one of the benefits of EnergyPLAN is the fact that it is an analytical model that simulates all energy sectors in an hourly resolution based on aggregated data, which makes it flexible in terms of introducing new technologies, such as the UEH sources used in this paper.

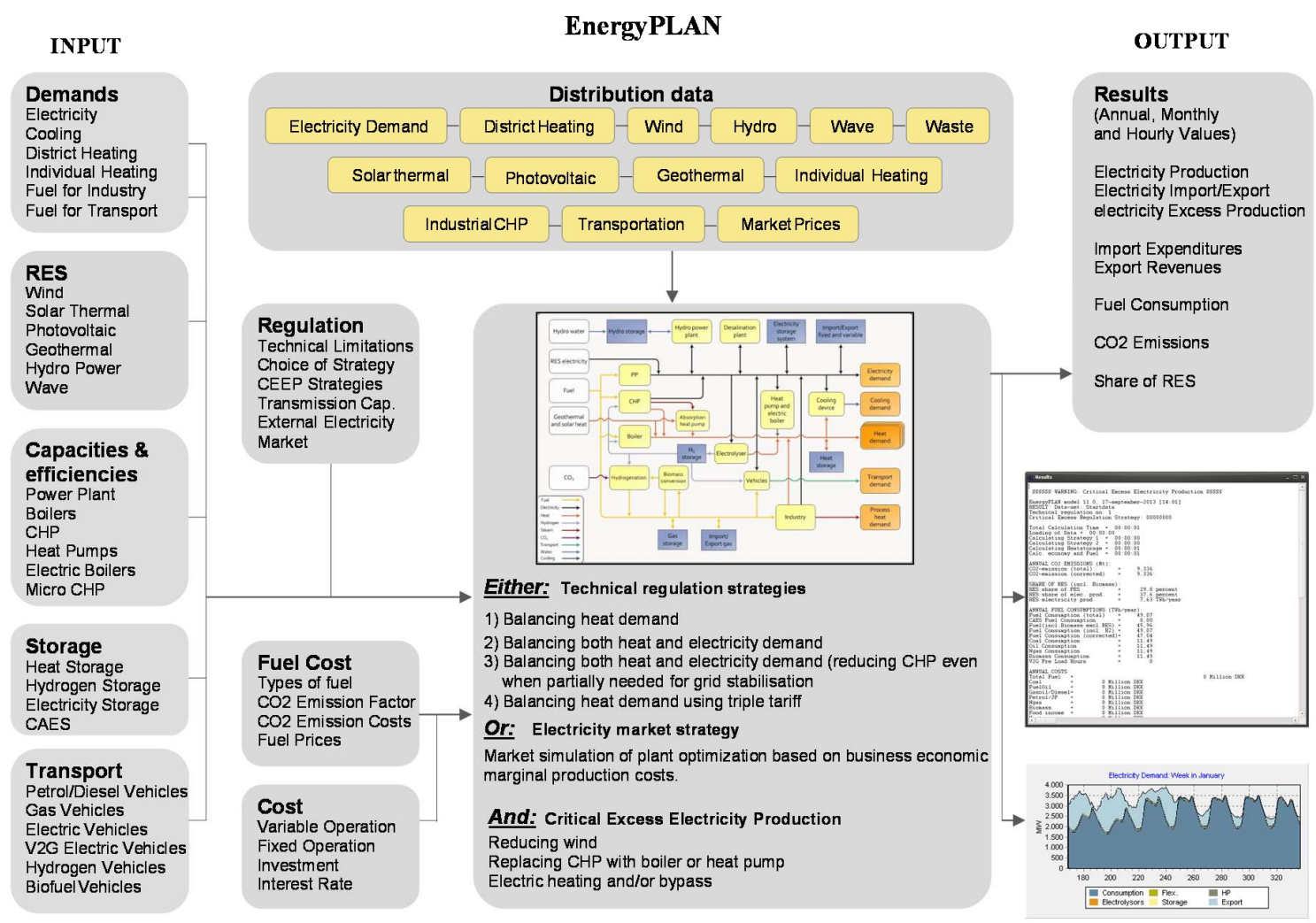

Figure 4. EnergyPLAN input and output categories, regulation strategies and distribution data [53].

\subsection{Assessment of Accessible Excess Heat and COP Values}

The annual available excess heat in $2 \mathrm{~km}$ proximity to DH networks and assumptions regarding the temporality of the sources are needed for the hourly energy system modelling. As the heat sources have different characteristics, different allocation methods have been used to estimate the temporal profiles for each heat source. The excess heat from data centers is derived from the cooling processes of IT equipment and is assumed to be air cooling systems. The excess heat from metros is from the exhaust ventilation tunnels and is assumed to be air source. The excess heat from service sector buildings is recovered from the ejection heat from cooling systems and is assumed to be air source. Finally, the excess heat from wastewater treatment is assumed to be water source. An overview of the different characteristics is presented in Table 2. 
Table 2. Assumptions used to estimate the temporal profiles of the four unconventional excess heat (UEH) sources.

\begin{tabular}{ccccc}
\hline & Data Center & Wastewater & Metro & Service Sector \\
\hline Max temp. $\left({ }^{\circ} \mathrm{C}\right)$ & 30 & 15 & 35 & 40 \\
Min temp. $\left({ }^{\circ} \mathrm{C}\right)$ & 25 & 8 & 5 & 25 \\
Cycle efficiency 2015 & 0.5 & 0.65 & 0.67 & 0.46 \\
Cycle efficiency 2050 & 0.55 & 0.72 & 0.74 & 0.51 \\
\hline
\end{tabular}

For data center cooling, a constant production is assumed, wastewater treatment uses a sine function of the COP, metro ventilation follows monthly values based on data in [39] and cooling in the service sector buildings follows the space cooling demands, applying profiles from [42]. In addition to the source temperatures, assumptions have also been used to calculate the COP for each source. First, the supply and return temperatures of the $\mathrm{DH}$ systems are expected to decrease in 2050 ; thus, $90 / 50{ }^{\circ} \mathrm{C}$ is used in 2015 and $75 / 40{ }^{\circ} \mathrm{C}$ in 2050 . Furthermore, the share of total theoretical COP is estimated using the temperature assumptions for each source. The 2015 values are based on [39] and in $2050 \mathrm{a}$ $10 \%$ increase to include technological improvements is accounted for. This approach gives the cycle efficiencies presented in Table 2. Lastly, the cooling of the heat source is assumed to be $5 \mathrm{~K}$, which is used in the COP calculations calculated assuming a Lorentz cycle because of the varying temperatures of the heat sources, see Equation (1).

$$
C O P=\eta_{L} * \eta_{C}
$$

where $\eta_{C}$ is the cycle efficiency presented above and $\eta_{L}$ is defined in Equation (2).

$$
\eta_{L}=\frac{T A_{H}}{T A_{H}-T A_{L}}
$$

In Equation (2) $T A_{H}$ refers to the logarithmic mean absolute temperature. Subscript $H$ refers to the high temperature side of the heat pump, referring to the condenser, and subscript $L$ refers to the low temperature side of the heat pump, which is the evaporator. $T A$ for either of the two is defined in Equation (3).

$$
T A=\frac{T A_{\text {in }}-T A_{\text {out }}}{\operatorname{Ln}\left(\frac{T A_{\text {in }}}{T A_{\text {out }}}\right)}
$$

For $T A_{H}$ the in and out values refer to the return and supply temperatures of $\mathrm{DH}$, respectively. For $T A_{L}$ the "in" value refers to the heat source temperature while the "out" value refers to the heat source temperature minus the $\Delta T$ of $5 \mathrm{~K}$.

The electricity consumption $(E)$ of the heat pump is calculated based on the COP and the available heat utilized $\left(H_{L}\right)$, see Equation (4).

$$
E=\frac{H_{L}}{C O P-1}
$$

The accessible heat $\left(H_{S}\right)$, meaning the heat produced by the heat pump, is defined in Equation (5).

$$
H_{S}=E+H_{L}
$$

Thus, the accessible heat equals the sum of the contribution of the electric pump and the heat from the heat source.

\section{Available and Accessible Heat Potentials}

This section presents the analysis of available and accessible heat potentials and is organized in the three parts presented in the analytical framework: The available excess heat, the accessible excess heat and the accessible excess heat within the national energy system context. 


\subsection{Available Excess Heat}

Data on the annually available excess heat from the four sources and for the three countries are used from the mapping performed in [39], see Table 3. The 2015 potentials are the potentials within $2 \mathrm{~km}$ of existing DH areas while the 2050 potentials are based on factors introduced such as assumed availability of resources and increase of the $\mathrm{DH}$ coverage in the three countries. For the source availability factors the increase to 3 for data centers is based on [54] and the increase in service sector cooling is based on the HRE4 project [42], while wastewater and metro remain unchanged. The DH access factors for 2050 are rough estimates based on the DH shares in the HRE4 project [42]. The $2 \mathrm{~km}$ distance to existing DH is assumed to include the UEH potentials that are near to DH, in [39] the potentials for the $5 \mathrm{~km}$ and $10 \mathrm{~km}$ distance are also assessed, but as the spatial analysis is not the main focus point of this paper, only the $2 \mathrm{~km}$ distance is used. Thus, the potentials are conservative estimates as the potential for UEH is naturally larger if larger search distances was applied.

Table 3. Available excess heat assumed to be located near potential DH areas, hence available to DH supply. The table shows the potentials divided into countries and heat sources for 2015 and the projections for 2050. The bold underlined values are the potentials used in the analysis.

\begin{tabular}{|c|c|c|c|c|c|c|}
\hline \multirow{2}{*}{$\begin{array}{c}\text { [TWh/year] } \\
\text { Waste heat source }\end{array}$} & \multicolumn{2}{|c|}{ Available Excess Heat 2015} & \multicolumn{2}{|c|}{ Factors Used between 2015 and 2050} & \multicolumn{2}{|c|}{ Available Excess Heat 2050} \\
\hline & $\begin{array}{l}\text { Total available } \\
\text { excess heat }\end{array}$ & $\begin{array}{l}\text { Geographical } \\
\text { available heat in } \\
2 \text { km distance }\end{array}$ & $\begin{array}{l}\text { Source availability } \\
\text { increase factor }\end{array}$ & $\begin{array}{l}\text { District heating } \\
\text { access factor }\end{array}$ & $\begin{array}{c}\text { Considering } \\
\text { source availability }\end{array}$ & $\begin{array}{l}\text { Considering both source } \\
\text { availability and district } \\
\text { heating access }\end{array}$ \\
\hline \multicolumn{7}{|c|}{ Germany } \\
\hline Data centers & 11.8 & 10.8 & 3.0 & 0.8 & 35.3 & 28.3 \\
\hline Wastewater & 46.1 & $\overline{22.4}$ & 1.0 & 0.8 & 46.1 & $\overline{36.8}$ \\
\hline Metros & 1.3 & $\overline{1.3}$ & 1.0 & 0.8 & 1.3 & $\overline{1.3}$ \\
\hline Service sector & $\underline{10.8}$ & $\overline{-}$ & 3.2 & 0.8 & 34.8 & $\overline{27.9}$ \\
\hline \multicolumn{7}{|c|}{ Spain } \\
\hline Data centers & 5.3 & 3.2 & 3.0 & 0.9 & 15.8 & $\underline{14.3}$ \\
\hline Wastewater & 17.8 & $\overline{4.2}$ & 1.0 & 0.9 & 17.8 & $\overline{\overline{16.1}}$ \\
\hline Metros & 2.2 & $\overline{1.9}$ & 1.0 & 0.9 & 2.2 & $\overline{2.0}$ \\
\hline Service sector & $\underline{32.4}$ & $\overline{-}$ & 2.1 & 0.9 & 68.8 & $\overline{61.9}$ \\
\hline \multicolumn{7}{|c|}{ France } \\
\hline Data centers & 10.1 & 8.5 & 3.0 & 0.7 & 30.2 & 21.1 \\
\hline Wastewater & 25.1 & $\overline{15.8}$ & 1.0 & 0.7 & 25.1 & $\overline{17.6}$ \\
\hline Metros & 2.2 & $\overline{\underline{2.1}}$ & 1.0 & 0.7 & 2.2 & $\overline{\underline{2.1}}$ \\
\hline Service sector & 14.2 & $\overline{-}$ & 3.3 & 0.7 & 46.6 & $\overline{32.6}$ \\
\hline
\end{tabular}

The bold underlines cells in Table 3 show the potentials used for both 2015 and 2050 and illustrate that the available excess heat in general for the 2050 scenarios is higher than in 2015 . This is due to the expected increasing resource availability and level of DH. It should also be noted that for the service sector buildings, the total available excess heat is used as it was not possible to identify the potential in $2 \mathrm{~km}$ distance to $\mathrm{DH}$.

Figure 5 shows the available excess heat potentials for 2015 within $2 \mathrm{~km}$ of DH in comparison to the total heat demand in each country. For data centers, the potential is around $1.5-2 \%$ of each national potential, while wastewater treatment is around 3\% in all countries. Metro stations have the lowest potentials of less than $1 \%$ of the total heat demands. The service sector shows large variations, as it has a potential of $1.3 \%$ in Germany, $2.9 \%$ in France and a potential of almost 22\% in Spain. 


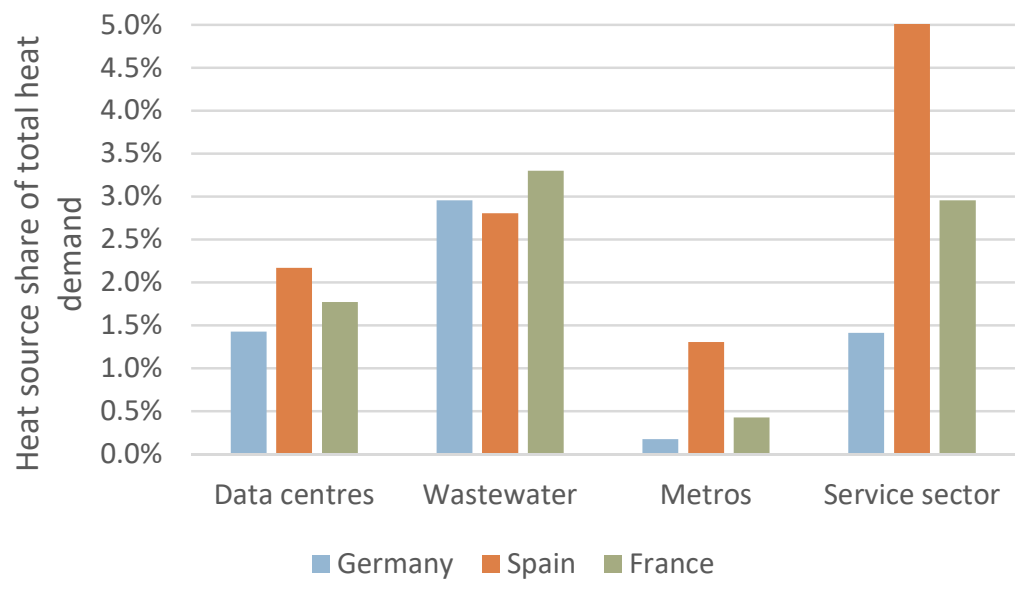

Figure 5. The available excess heat source potentials as a share of the total heat demands for 2015. Service sector cooling in Spain is $22 \%$.

\subsection{Accessible Excess Heat}

From the annual quantities of available heat, the next step is to find the hourly availability of each heat source. Figure 6 shows the resulting temporal profiles for each heat source, using Germany as an example. The service sector cooling and metro ventilation are mainly available in the summer, while data center cooling and wastewater treatment is available most of the year. The potentials are similar in the two other countries. However, as the total potential of each heat source is different, the shares of the total heat demands will be different. Given the temperature level of each source and the DH supply temperatures, presented in Section 2.4, the heat pump SCOP values are found.

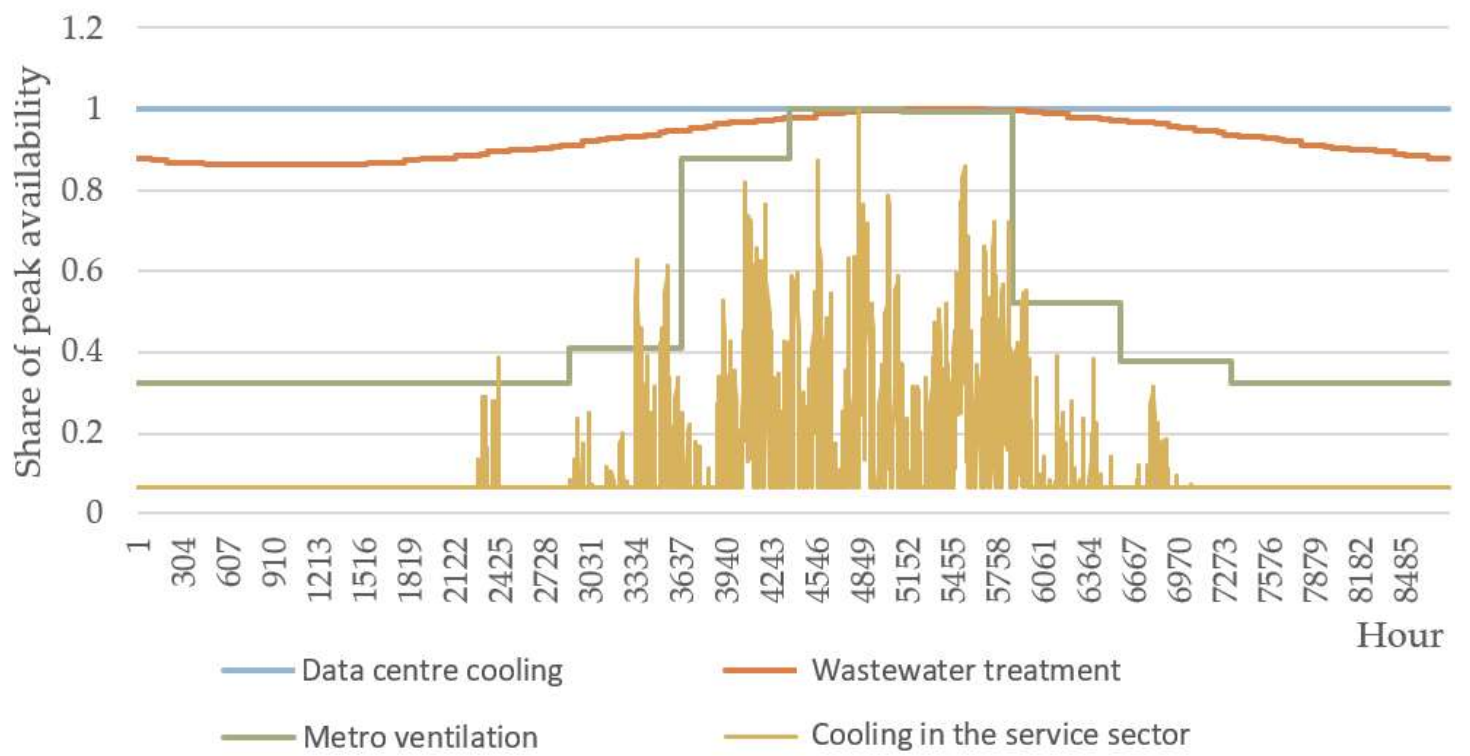

Figure 6. Hourly profiles for the four excess heat sources (using Germany 2050 as an example).

\subsection{Accessible Excess Heat in National Energy Systems}

The analysis of accessible excess heat in the national energy systems is quite comprehensive in terms of hourly information. Therefore, Figure 7 shows an example of how the hourly production profile looks for Germany in one week of February, in the 2050 scenarios. In general, the CHP plants produce heat when there is an electricity demand, while heat pumps and electric boilers produce when there is power production from wind and solar (not shown in the figure). When these renewable 
electricity sources are unavailable, the fuel boilers will produce the heat. This production profile shows how the different sources are prioritized, where the conventional excess heat, geothermal and solar thermal have priority, followed by the heat sources based on heat pumps. Thus, it will be a challenge to implement the UEH sources in DH areas with a large utilization of the conventional sources.

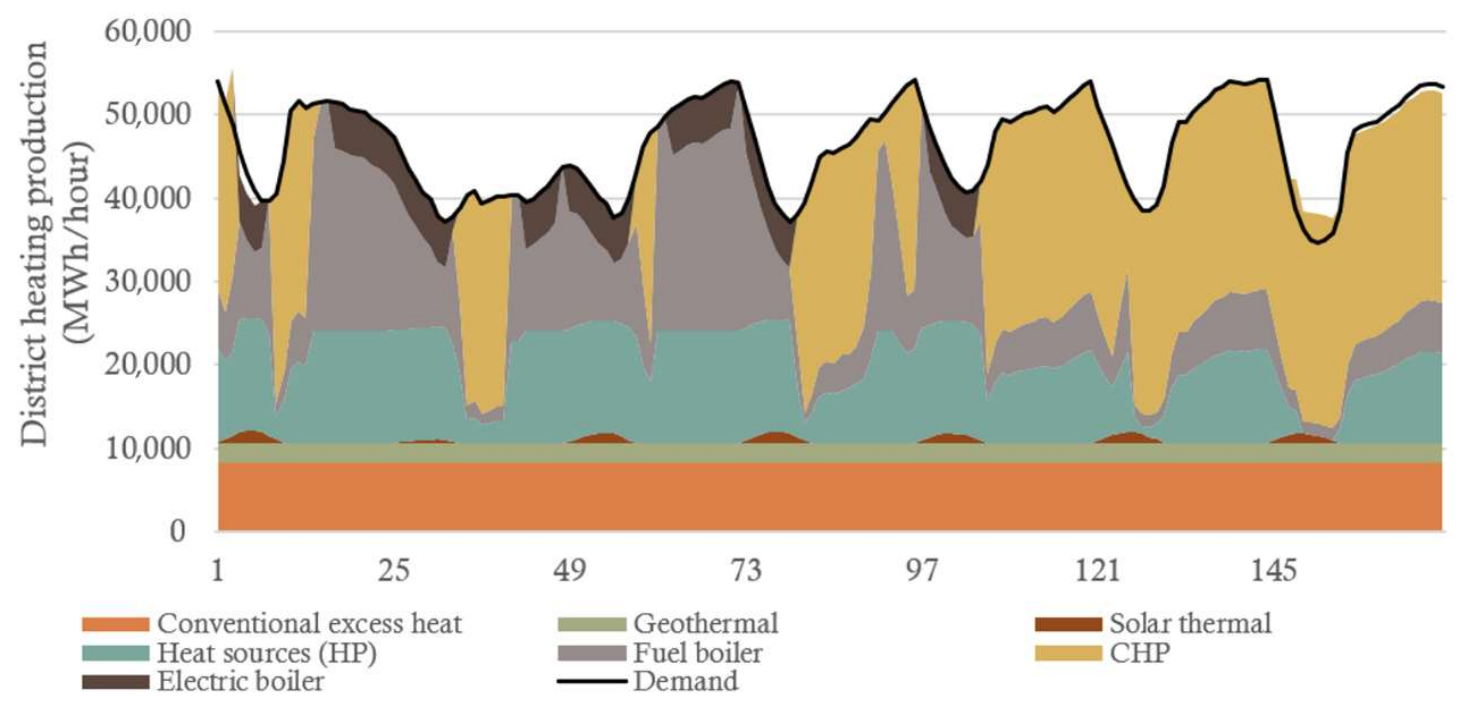

Figure 7. District heating production in Germany for a week in February from the 2050 scenario.

Figure 8 shows the accessible excess heat for the four sources in Spain as weekly averages over the year compared to the DH demand. Here it is clear that even though there is a large available share of service sector cooling in the summer, the accessible heat is significantly lower as this potential is not needed in the DH system.

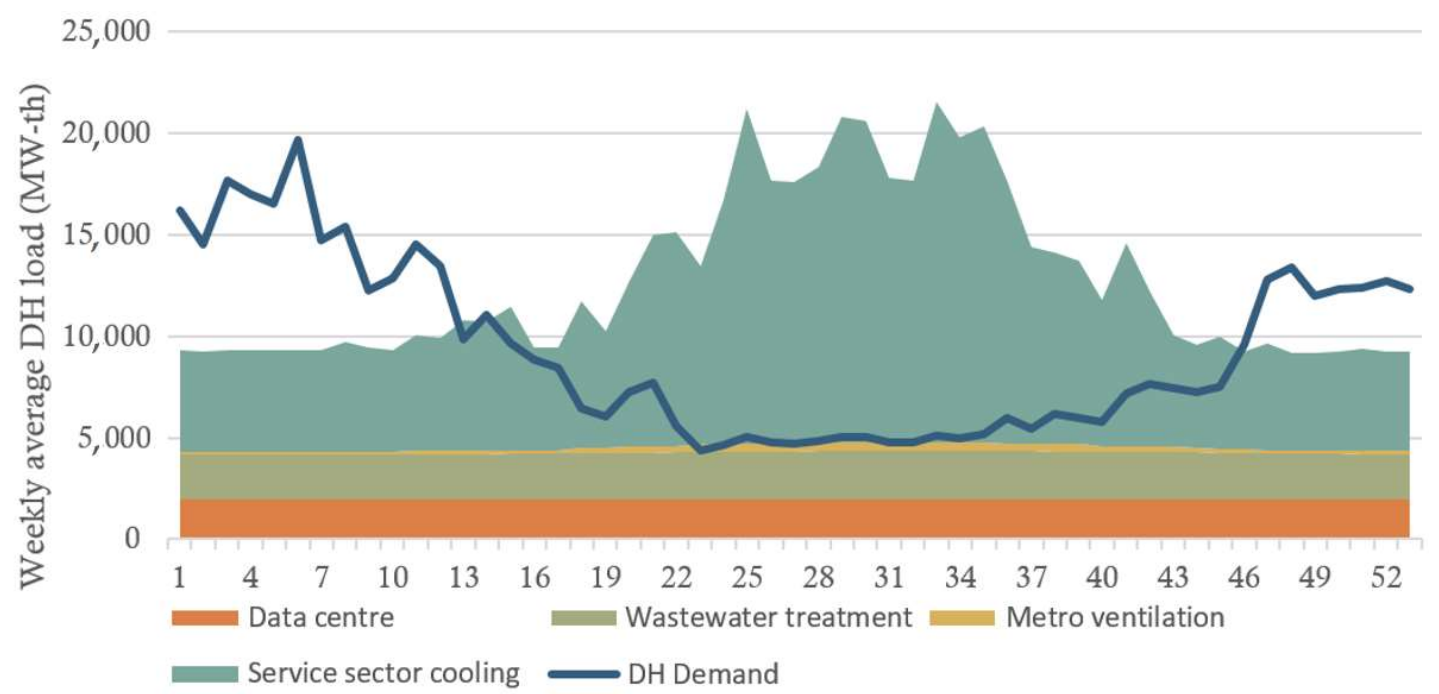

Figure 8. Accessible heat of the four heat sources in Spain in 2050 and the heat demand on weekly resolution.

\section{Results}

As the UEH sources are part of the same energy systems, they have also been analyzed in combined scenarios, which is the focus of the results section. Table 4 shows the main results of these combined scenarios, where the four sources have been added in an economically feasible way, giving priority to the least cost sources first. The results show that utilizing the UEH sources can reduce the primary 
energy supply in all countries; however, the potential is higher in 2050 compared to 2015, mainly due to the DH coverage being larger in 2050. However, in this regard France is an exception as the potential is higher in 2015 than 2050, which is due to favorable conditions for the heat pumps due to a relatively large nuclear power production. In 2050, France is more restricted in terms of implementing the UEH sources due to a large base-load share of conventional excess heat as well as geothermal heat. Thus, France is a good example of the importance of considering the national energy systems and not only focus on resources in a local context.

Table 4. Summary of key indicators from the combined country scenarios for 2015 and 2050.

\begin{tabular}{cccccccc}
\hline \multirow{2}{*}{ Key Indicator } & \multirow{2}{*}{ Unit } & \multicolumn{2}{c}{ Germany } & \multicolumn{2}{c}{ Spain } & \multicolumn{2}{c}{ France } \\
\cline { 3 - 8 } & & $\mathbf{2 0 1 5}$ & $\mathbf{2 0 5 0}$ & $\mathbf{2 0 1 5}$ & $\mathbf{2 0 5 0}$ & $\mathbf{2 0 1 5}$ & $\mathbf{2 0 5 0}$ \\
\hline Primary energy supply & TWh & 3371 & 2510 & 1319 & 1416 & 2813 & 2290 \\
Reduction & TWh & 3 & 29 & 2 & 10 & 7 & 7 \\
Energy system costs & B€ & 200 & 215 & 73 & 114 & 143 & 175 \\
Reduction & M€ & -11 & 575 & 15 & 62 & 166 & 60 \\
Utilized accessible excess heat & TWh & 8.2 & 34.7 & 3.7 & 13.5 & 9.2 & 8.6 \\
\hline
\end{tabular}

Figure 9 shows the total accessible heat and feasible utilization in the three countries for the combined 2050 scenarios. The values in the feasible utilization are significantly lower than found in the available heat scenarios. The reason is that with feasible utilization, the potential has been reduced as the heat pumps are only operated when it is feasible in the energy system. In all countries, the excess heat from the service sector is significantly reduced due to the excess heat sources being available in periods when the buildings have low heat demands. The data center and wastewater treatment are reduced less because of a more constant production profile over the year.

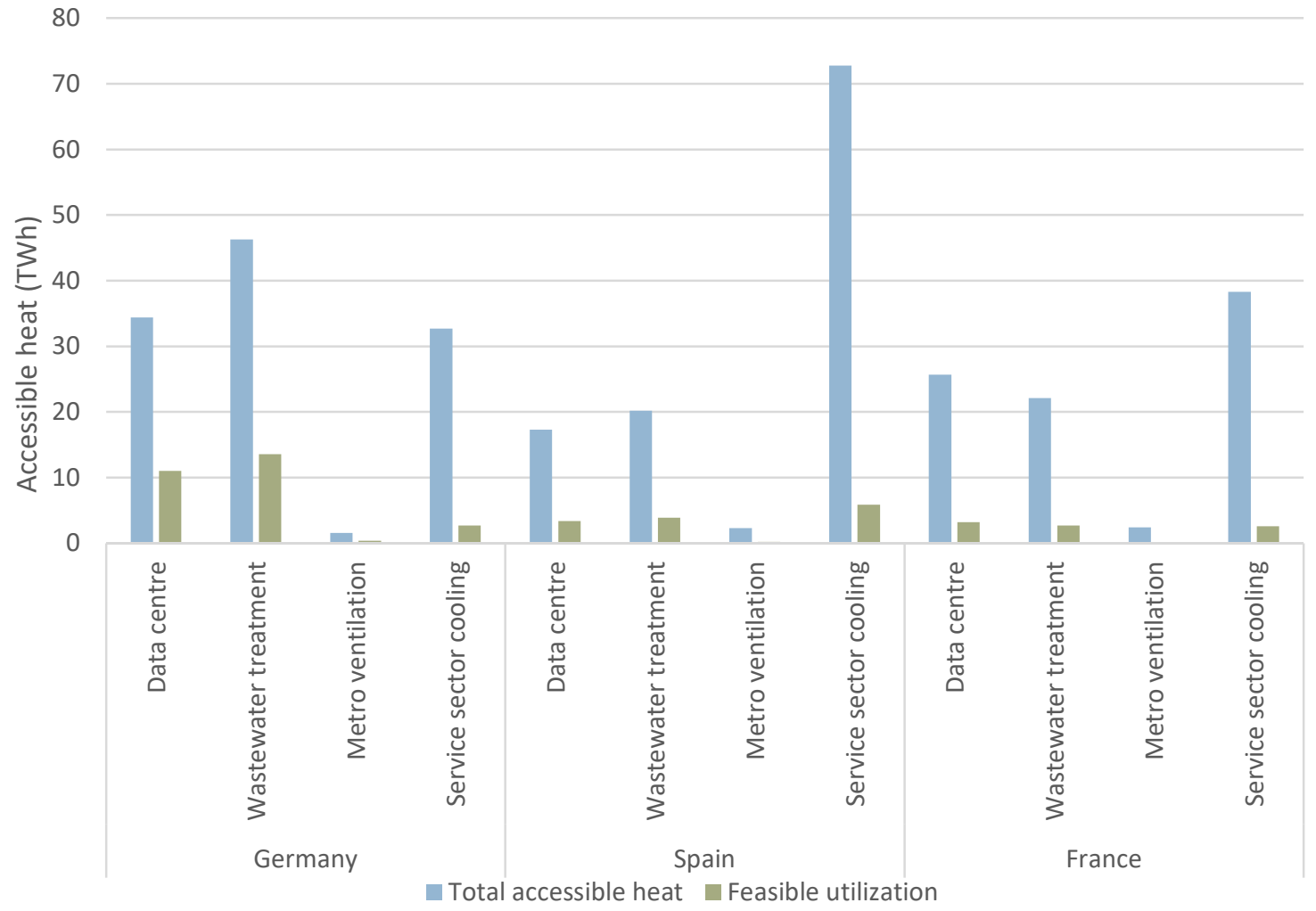

Figure 9. Accessible heat for the different scenarios, heat sources and countries in 2050. 
Figure 10 shows the same results but focuses on the feasible share of the total accessible heat demand for each country and heat source. The feasible share is lower than $10 \%$ for service sector buildings in all three countries. Metro ventilation is lower than 10\% in Spain and France, while it is almost $25 \%$ in Germany, which is a result of a lower accessible potential with a higher heat demand. For data centers and wastewater treatment the feasible shares are similar by country, but different between countries with a feasible share around 30\% in Germany, 20\% in Spain and 12\% in France.

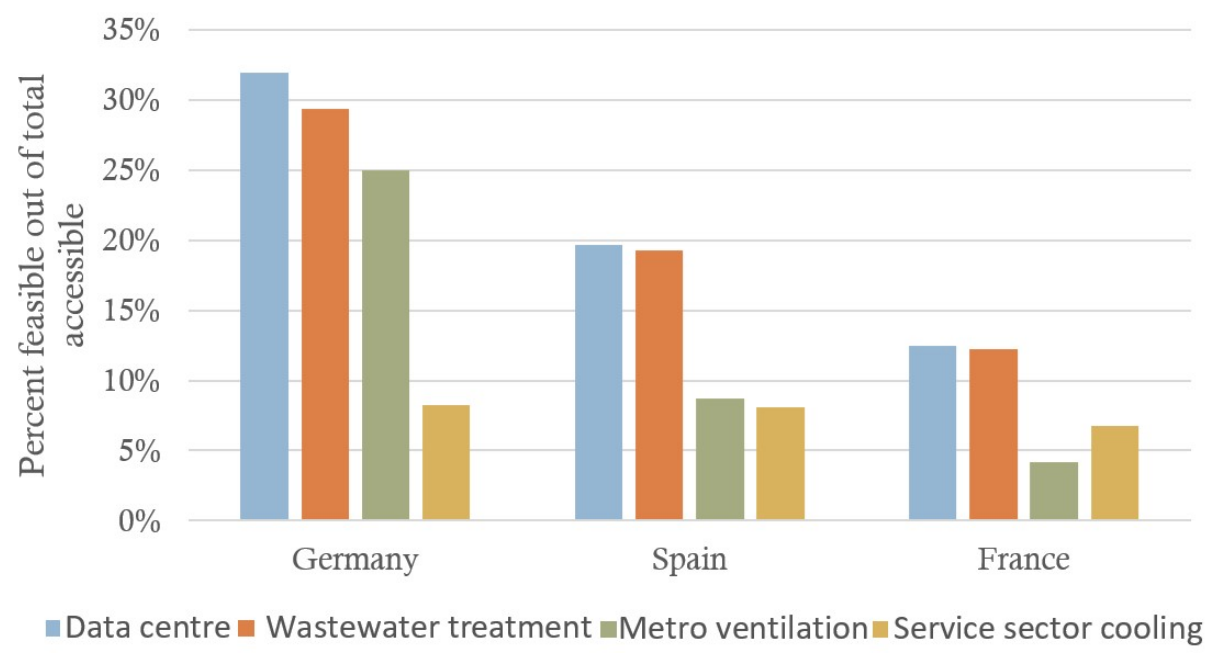

Figure 10. Feasible share of total accessible heat for the different heat sources and countries in 2050.

\section{Discussion}

Analyzing the integration of UEH sources in national energy systems is complex, and thus there are many relevant aspects to discuss in relation to both the results and the assumptions behind the analysis. First, we will focus on the results followed by a discussion on the assumptions and methodology.

In general, the results show a potential for excess heat from available UEH in all three countries. The spatial dimension is important when examining the potential for $\mathrm{DH}$, and selecting the UEH within proximity of DH excludes part of the total available UEH. As this is highly related to the local areas, and the locations of both $\mathrm{UEH}$ and $\mathrm{DH}$, the impact of including proximity as a selection criterion will be different in each case. Furthermore, when considering what is feasible to use in the energy system, the use of the UEH is further reduced, mainly related to the temporality of supply and demand. The results show that the limiting factors for UEH feasibility is related to competition with other heat supply sources, the heat demand and the UEH availability. For example, the results for France show that due to large amounts of conventional excess heat in the 2050 scenario, the UEH sources are limited to between $4-12 \%$ of the total accessible excess heat. Another example is in Germany where the potential from data centers, wastewater treatment and metros is higher because of the higher heat demand in the country. Therefore, it is recommended that all these aspects are considered when determining if UEH is relevant in a specific location.

Modelling of national energy systems implies using generalizations and assumptions. The mapping contains uncertainties in the 2050 scenarios, as the UEH potential is based on the location of existing DH systems, a DH availability factor and a source availability factor for each country. If the development of $\mathrm{DH}$ and each resource is different from these factors, it would have a significant influence on the available excess heat. Another challenge in relation to the mapping is the data availability, especially for data centers and information on the service sector buildings.

The energy system analysis contains some generalizations, especially in the modelling of DH. In reality, there would be various DH systems across the countries, however in EnergyPLAN there is no differentiation between the individual DH systems in each country. This implies some uncertainties as DH systems are local solutions with varying potentials. Large DH systems have the benefit of 
potentially being able to utilize large amounts of excess heat; however, in many of these systems, other low-cost baseload production units might be available, reducing the feasibility of the UEH sources. However, in large DH systems without large amounts of low-cost heat, the potentials could be favorable for heat pumps utilizing UEH. In small DH networks, having large low-cost baseload production units is less likely; but here the challenge is that renewable sources such as solar thermal is more dominant, also challenging the UEH sources. Still, it could also benefit the sources, e.g., if seasonal heat storages are available then heat pumps can be used to both boost the solar thermal production and the UEH sources. Nevertheless, it is important to examine the local conditions in more detail, also considering the barriers related to both regulation and taxation in the specific countries, which could have a high influence on the business economic potential of utilizing the heat sources.

Another limitation of the analysis is the scenarios used for 2050, which are based on introducing large amounts of renewables, electrification of transport and industry and a general shift away from fossil fuels in all sectors. However, the systems are not fully renewable and following the smart energy system design. In scenarios designed with a focus on smart energy systems and $100 \%$ renewable energy, the potential for large heat pumps would be even more relevant than what is studied in this analysis. This is mainly due to a larger focus on sector integration, making the operation of CHP plants more flexible and reducing the need for these to provide baseload production, making more room for other sources such as heat pumps.

Still, having considered all of these methodological limitations and generalizations, the analysis contributes with new knowledge in regard to the utilization of UEH on a national level, where it clearly shows a feasible potential for the sources but also a large difference between available and accessible excess heat. It is vital to include the energy systems analysis to consider the temporality of the UEH sources and the energy system they will be integrated into. Thus, it is also evident to consider the future energy system, as this also has a potential influence on the feasibility.

\section{Conclusions}

This paper examines the potential of integrating four UEH sources in DH systems, within a national context, and with the aim of lowering the emissions and economic costs of the energy systems. The four UEH sources are data centers, wastewater treatment, metros, and service sector buildings, while the three countries studied are Germany, Spain and France. Furthermore, the potentials are evaluated in scenarios for both 2015 and 2050 from the Heat Roadmap Europe 4 project.

The analysis shows that the UEH source potentials are affected by various factors, such as location, temporality and DH supply. The UEH sources need to be in proximity to DH to be utilized for DH purposes. The hourly availability of each UEH source is important as the heat demand is typically highest in the winter, which means that excess heat sources available in the winter (data centers and wastewater) fit better with the heat demand profile, compared to sources primarily available in the summer (metro and service sector). Finally, in terms of DH supply, the feasibility of UEH can be challenged in DH systems with large amounts of low-cost conventional excess heat, solar thermal or geothermal production.

The country analyses show that in all the national systems UEH sources are feasible, especially where the excess heat can replace heat production in conventional heat boilers. Germany has the largest potential for UEH, which is due to both availability and a higher heat demand. In France, the utilization share is low, which is due to the competition of other heat supply sources, as the HRE scenarios for 2050 include a large share of conventional excess heat.

In general, the results show that using these sources can both reduce primary energy use and the costs of the energy system, mainly in terms of reducing fuel consumption in the DH systems. It is also evident that UEH only has a minor impact on the overall energy system, as it can be considered a supplement to other kinds of heat supply in a small part of the system. In the local DH systems, the impact of UEH will be more visible as it plays a larger role in DH systems than in the overall energy system. From the perspective of the total national energy system, it is important that the 
heat pumps are able to operate flexibly to enable the integration of renewables and to replace fuel consumption effectively.

In the wider scope, utilizing UEH can be expected to have an impact on the planning of new DH systems, as it is part of the transition to a more sustainable heat supply. In many countries, the transition requires a shift in the approach to planning heating systems. In mature DH countries, the focus would be on changing the planning practices and regulatory framework to acknowledge UEH sources, while in countries with no DH a shift is needed towards realizing that $\mathrm{DH}$ is a viable and sustainable solution.

Finally, in terms of future research, there are simplifications and assumptions in the methodology and analysis, that should be developed in future work. The spatial dimensions of UEH availability and the different types of district heating systems at national level could be analyzed in more detail. Another aspect is that even though 2050 scenarios are analyzed, these still include fossil fuels, and thus it could be of particular interest to analyze scenarios following the sustainable energy systems concept and 100\% renewable energy systems, as this seems to be the focus in many 2050 scenarios of today.

Author Contributions: Conceptualization, S.N., K.H., and R.L.; methodology, S.N., K.H., and R.L.; software, K.H., R.L.; validation, S.N.; formal analysis, K.H. and R.L.; investigation, K.H. and R.L.; resources, K.H. and R.L.; data curation, K.H. and R.L.; writing-original draft preparation, S.N. and D.M.; writing-review and editing, S.N., K.H., R.L, and D.M.; visualization, S.N.; supervision, S.N.; project administration, S.N.; funding acquisition, R.L. All authors have read and agreed to the published version of the manuscript.

Funding: This article was developed based on the work carried out in the ReUseHeat project funded by the European Union's Horizon 2020 research and innovation program under grant agreement No 767429.

Conflicts of Interest: The authors declare no conflict of interest.

\section{Nomenclature}

$\begin{array}{ll}\mathrm{CO}_{2} & \text { Carbon Dioxide } \\ \mathrm{COP} & \text { Coefficient of Performance } \\ \mathrm{CPH} & \text { Combined Heat and Power } \\ \mathrm{DH} & \text { District Heating } \\ \mathrm{HRE} 4 & \text { Heat Roadmap Europe } 4 \\ I E A & \text { International Energy Agency } \\ S C O P & \text { Seasonal Coefficient of Performance } \\ U E H & \text { Unconventional Excess Heat }\end{array}$

\section{References}

1. UNFCCC. Paris Agreement. Int. Leg. Mater. 2016, 55, 740-755. [CrossRef]

2. Connolly, D.; Lund, H.; Mathiesen, B.V.; Østergaard, P.A.; Möller, B.; Nielsen, S.; Ridjan, I.; Hvelplund, F.; Sperling, K.; Karnøe, P.; et al. Smart Energy Systems: Holistic and Integrated Energy Systems for the Era of 100\% Renewable Energy. Available online: http://vbn.aau.dk/files/78422810/Smart_Energy_Systems_ Aalborg_University.pdf (accessed on 24 September 2020).

3. Paardekooper, S.; Lund, R.S.; Lund, H. Smart Energy Systems. In Energy Storage Options and Their Environmental Impact; Hester, R., Harrison, R., Eds.; Royal Society of Chemistry: London, UK, 2018; pp. $228-260$.

4. Connolly, D.; Hansen, K.; Drysdale, D.; Lund, H.; Mathiesen, B.V.; Werner, S.; Persson, U.; Möller, B.; Wilke, O.G.; Bettgenhäuser, K.; et al. Definition of large-scale HP, capacities, refrigerants, heat source, T. In STRATEGO-Enhanced Heating and Cooling Plans to Quantify the Impact of Increased Energy Efficiency in EU Member States; Aalborg University: Aalborg, Denmark, 2016; p. 187. Available online: https: //www.euroheat.org/wp-content/uploads/2016/04/WP2-Main-Report.pdf (accessed on 24 September 2020).

5. Lund, H.; Østeraard, P.A.; Chang, M.; Werner, S.; Svendsen, S.; Sorknæs, P.; Thorsen, J.E.; Hvelplund, F.; Mortensen, B.O.G.; Mathiesen, B.V.; et al. The status of 4th generation district heating: Research and results. Energy 2018, 164, 147-159. [CrossRef] 
6. Lund, H.; Werner, S.; Wiltshire, R.; Svendsen, S.; Thorsen, J.E.; Hvelplund, F.; Mathiesen, B.V. 4th Generation District Heating (4GDH): Integrating smart thermal grids into future sustainable energy systems. Energy 2014, 68, 1-11. [CrossRef]

7. Ziemele, J.; Kalnins, R.; Vigants, G.; Vigants, E.; Veidenbergs, I. Evaluation of the industrial waste heat potential for its recovery and integration into a fourth generation district heating system. Energy Procedia 2018, 147, 315-321. [CrossRef]

8. Lund, R.; Persson, U. Mapping of potential heat sources for heat pumps for district heating in Denmark. Energy 2016, 110, 129-138. [CrossRef]

9. Sawalha, S. Investigation of heat recovery in $\mathrm{CO}_{2}$ trans-critical solution for supermarket refrigeration. Int. J. Refrig. 2013, 36, 145-156. [CrossRef]

10. Rezaie, B.; Rosen, M.A. District heating and cooling: Review of technology and potential enhancements. Appl. Energy 2012. [CrossRef]

11. Miró, L.; Brückner, S.; Cabeza, L.F. Mapping and discussing Industrial Waste Heat (IWH) potentials for different countries. Renew. Sustain. Energy Rev. 2015, 51, 847-855. [CrossRef]

12. Naegler, T.; Simon, S.; Klein, M.; Gils, H.C. Quantification of the European industrial heat demand by branch and temperature level. Int. J. Energy Res. 2015, 39, 2019-2030. [CrossRef]

13. McKenna, R.C.; Norman, J.B. Spatial modelling of industrial heat loads and recovery potentials in the UK. Energy Policy 2010, 38, 5878-5891. [CrossRef]

14. Bühler, F.; Petrović, S.; Karlsson, K.; Elmegaard, B. Industrial excess heat for district heating in Denmark. Appl. Energy 2017, 205, 991-1001. [CrossRef]

15. Dénarié, A.; Muscherà, M.; Calderoni, M.; Motta, M. Industrial excess heat recovery in district heating: Data assessment methodology and application to a real case study in Milano, Italy. Energy 2019, 166, 170-182. [CrossRef]

16. Brückner, S.; Schäfers, H.; Peters, I.; Lävemann, E. Using industrial and commercial waste heat for residential heat supply: A case study from Hamburg, Germany. Sustain. Cities Soc. 2014, 13, 139-142. [CrossRef]

17. Fang, H.; Xia, J.; Jiang, Y. Key issues and solutions in a district heating system using low-grade industrial waste heat. Energy 2015, 86, 589-602. [CrossRef]

18. Dou, Y.; Togawa, T.; Dong, L.; Fujii, M.; Ohnishi, S.; Tanikawa, H.; Fujita, T. Innovative planning and evaluation system for district heating using waste heat considering spatial configuration: A case in Fukushima, Japan. Resour. Conserv. Recycl. 2018, 128, 406-416. [CrossRef]

19. Ivner, J.; Broberg Viklund, S. Effect of the use of industrial excess heat in district heating on greenhouse gas emissions: A systems perspective. Resour. Conserv. Recycl. 2015, 100, 81-87. [CrossRef]

20. Olsson, L.; Wetterlund, E.; Söderström, M. Assessing the climate impact of district heating systems with combined heat and power production and industrial excess heat. Resour. Conserv. Recycl. 2015, 96, 31-39. [CrossRef]

21. Brueckner, S.; Miró, L.; Cabeza, L.F.; Pehnt, M.; Laevemann, E. Methods to estimate the industrial waste heat potential of regions-A categorization and literature review. Renew. Sustain. Energy Rev. 2014, 38, 164-171. [CrossRef]

22. Lygnerud, K.; Werner, S. Risk assessment of industrial excess heat recovery in district heating systems. Energy 2018, 151, 430-441. [CrossRef]

23. Broberg Viklund, S. Energy efficiency through industrial excess heat recovery-Policy impacts. Energy Effic. 2015, 8, 19-35. [CrossRef]

24. Patil, A.; Ajah, A.; Herder, P. Recycling industrial waste heat for sustainable district heating: A multi-actor perspective. Int. J. Environ. Technol. Manag. 2009, 10, 412-426. [CrossRef]

25. Broberg, S.; Backlund, S.; Karlsson, M.; Thollander, P. Industrial excess heat deliveries to Swedish district heating networks: Drop it like it's hot. Energy Policy 2012, 51, 332-339. [CrossRef]

26. Spriet, J.; McNabola, A.; Neugebauer, G.; Stoeglehner, G.; Ertl, T.; Kretschmer, F. Spatial and temporal considerations in the performance of wastewater heat recovery systems. J. Clean. Prod. 2020, 247, 119583. [CrossRef]

27. Somogyi, V.; Sebestyén, V.; Domokos, E. Assessment of wastewater heat potential for district heating in Hungary. Energy 2018, 163, 712-721. [CrossRef] 
28. Huang, P.; Copertaro, B.; Zhang, X.; Shen, J.; Löfgren, I.; Rönnelid, M.; Fahlen, J.; Andersson, D.; Svanfeldt, M. A review of data centers as prosumers in district energy systems: Renewable energy integration and waste heat reuse for district heating. Appl. Energy 2020, 258, 114109. [CrossRef]

29. Oró, E.; Taddeo, P.; Salom, J. Waste heat recovery from urban air cooled data centres to increase energy efficiency of district heating networks. Sustain. Cities Soc. 2019, 45, 522-542. [CrossRef]

30. He, Z.; Ding, T.; Liu, Y.; Li, Z. Analysis of a district heating system using waste heat in a distributed cooling data center. Appl. Therm. Eng. 2018, 141, 1131-1140. [CrossRef]

31. Wahlroos, M.; Pärssinen, M.; Rinne, S.; Syri, S.; Manner, J. Future views on waste heat utilization-Case of data centers in Northern Europe. Renew. Sustain. Energy Rev. 2018, 82, 1749-1764. [CrossRef]

32. Wahlroos, M.; Syri, S.; Pärssinen, M.; Manner, J. Utilizing data center waste heat in district heating-Impacts on energy efficiency and prospects for low-temperature district heating networks. Energy 2017, 140, 1228-1238. [CrossRef]

33. Petrović, S.; Colangelo, A.; Balyk, O.; Delmastro, C.; Gargiulo, M.; Simonsen, M.B.; Karlsson, K. The role of data centres in the future Danish energy system. Energy 2020, 194, 116928. [CrossRef]

34. Davies, G.; Boot-Handford, N.; Curry, D.; Dennis, W.; Ajileye, A.; Revesz, A.; Maidment, G. Combining cooling of underground railways with heat recovery and reuse. Sustain. Cities Soc. 2019, 45, 543-552. [CrossRef]

35. Andrés, M.; Regidor, M.; Macía, A.; Vasallo, A.; Lygnerud, K. Assessment methodology for urban excess heat recovery solutions in energy-efficient District Heating Networks. Energy Procedia 2018, 149, 39-48. [CrossRef]

36. Zühlsdorf, B.; Christiansen, A.R.; Holm, F.M.; Funder-Kristensen, T.; Elmegaard, B. Analysis of possibilities to utilize excess heat of supermarkets as heat source for district heating. Energy Procedia 2018, 149, $276-285$. [CrossRef]

37. ReUseHeat ReUseHeat Project. Available online: https://www.reuseheat.eu (accessed on 1 July 2020).

38. Lund, R.; Hansen, K. Urban Excess Heat Utilization in Future Energy Systems. Available online: https://www. reuseheat.eu/wp-content/uploads/2019/03/D1.5-Energy-planning-analysis.pdf (accessed on 1 July 2020).

39. Persson, U.; Averfalk, H. Accessible Urban Waste Heat, ReUseHeat Deliverable 1.4. Available online: https://www.reuseheat.eu/wp-content/uploads/2019/02/D1.4-Accessible-urban-waste-heat.pdf (accessed on 24 September 2020).

40. Nijs, W.; Castelló, P.R.; González, I.H. Heat Roadmap Europe. Baseline Scenario of the Total Energy System Up to 2050. Available online: https://heatroadmap.eu/wp-content/uploads/2018/11/HRE4_D5.2.pdf (accessed on 24 September 2020).

41. Euroheat \& Power Country by Country 2017. Available online: https://www.euroheat.org/cbc/2017/ (accessed on 18 September 2020).

42. Paardekooper, S.; Lund, R.S.; Mathiesen, B.V.; Chang, M.; Petersen, U.R.; Grundahl, L.; David, A.; Dahlbæk, J.; Kapetanakis, J.; Lund, H.; et al. Quantifying the Impact of Low-carbon Heating and Cooling Roadmaps. Heat Roadmap Europe Beliverable 6.4. 2018. Available online: https://heatroadmap.eu/roadmaps (accessed on 24 September 2020).

43. Heat Roadmap Europe HRE4 Cost Database. Available online: https:/heatroadmap.eu/wp-content/uploads/ 2019/02/HRE4-cost-database.xlsx (accessed on 27 February 2019).

44. Guddat, M.G.A.; Sørensen, S.S.; Trier, D.; Paardekooper, S. Review of the Cost Variation in Energy Plants across the $14 \mathrm{MSs}$; Heat Roadmap Europe Deliverable 6.2; PlanEnergi: Copenhagen, Denmark, 2017; Available online: https:/heatroadmap.eu/wp-content/uploads/2018/12/D6.2-Review-of-the-cost-variationin-energy-plants-across-the-14-MSs..pdf (accessed on 24 September 2020).

45. International Energy Agency IEA. World Energy Outlook 2017; IEA: Paris, France, 2017; Available online: https://www.iea.org/reports/world-energy-outlook-2017 (accessed on 24 September 2020).

46. Ringkjøb, H.-K.; Haugan, P.M.; Solbrekke, I.M. A review of modelling tools for energy and electricity systems with large shares of variable renewables. Renew. Sustain. Energy Rev. 2018, 96, 440-459. [CrossRef]

47. Connolly, D.; Lund, H.; Mathiesen, B.V.; Leahy, M. A review of computer tools for analysing the integration of renewable energy into various energy systems. Appl. Energy 2010, 87, 1059-1082. [CrossRef]

48. Oberle, S.; Elsland, R. Are open access models able to assess today's energy scenarios? Energy Strateg. Rev. 2019, 26, 100396. [CrossRef] 
49. Lund, H. EnergyPLAN-Advanced Energy Systems Analysis Computer Model; Documentation Version 14.0; Sustainable Energy Planning Research Group, Aalborg University: Aalborg, Denmark, 2018; Available online: https://www.energyplan.eu/wp-content/uploads/2018/11/EnergyPLAN-DocumentationVersion14_final.pdf (accessed on 24 September 2020).

50. Thellufsen, J.Z.; Nielsen, S.; Lund, H. Implementing cleaner heating solutions towards a future low-carbon scenario in Ireland. J. Clean. Prod. 2019, 214, 377-388. [CrossRef]

51. Sorknæs, P.; Lund, H.; Skov, I.R.; Djørup, S.; Skytte, K.; Morthorst, P.E.; Fausto, F. Smart Energy Markets-Future electricity, gas and heating markets. Renew. Sustain. Energy Rev. 2020, 119, 109655. [CrossRef]

52. Nielsen, S.; Thellufsen, J.Z.; Sorknæs, P.; Djørup, S.R.; Sperling, K.; Østergaard, P.A.; Lund, H. Smart energy aalborg: Matching end-use heat saving measures and heat supply costs to achieve least-cost heat supply. Int. J. Sustain. Energy Plan. Manag. 2020, 25, 13-32. [CrossRef]

53. Lund, H. Renewable Energy Systems: A Smart Energy Systems Approach to the Choice and Modeling of 100\% Renewable Solutions: Second Edition; Elsevier Inc.: Amsterdam, The Netherlands, 2014; ISBN 9780124104235.

54. Jones, N. How to stop data centres from gobbling up the world's electricity. Nature 2018, 561, $163-166$. [CrossRef]

(C) 2020 by the authors. Licensee MDPI, Basel, Switzerland. This article is an open access article distributed under the terms and conditions of the Creative Commons Attribution (CC BY) license (http://creativecommons.org/licenses/by/4.0/). 